\title{
Differential effects of left/right neuropathy on rats' anxiety and cognitive behavior
}

\author{
Hugo Leite-Almeida a,b , João José Cerqueira ${ }^{\mathrm{a}, \mathrm{b}}$, Hong Wei $^{\mathrm{c}}$, Nuno Ribeiro-Costa ${ }^{\mathrm{a}, \mathrm{b}}$, \\ Helena Anjos-Martins ${ }^{\mathrm{a}, \mathrm{b}}$, Nuno Sousa ${ }^{\mathrm{a}, \mathrm{b}}$, Antti Pertovaara ${ }^{\mathrm{c}}$, Armando Almeida ${ }^{\mathrm{a}, \mathrm{b}, *}$ \\ ${ }^{a}$ Life and Health Sciences Research Institute (ICVS), School of Health Sciences, University of Minho, Braga, Portugal \\ ' ICVS/3B's-PT Government Associate Laboratory, Braga/Guimarães, Portugal \\ 'Biomedicum Helsinki, Institute of Biomedicine/Physiology, University of Helsinki, Helsinki, Finland
}

Sponsorships or competing interests that may be relevant to content are disclosed at the end of this article.

\section{A R T I C L E I N F O}

Article history:

Received 16 December 2011

Received in revised form 21 June 2012

Accepted 5 July 2012

Available online $\mathrm{xxxx}$

\section{Keywords:}

Cognitive behavior

Emotional behavior

Lateralization

Neuropathic pain

Rodent

\begin{abstract}
A B S T R A C T
Chronic pain is frequently accompanied by a deterioration of emotional behavior and cognitive function. A small number of studies in humans concluded that pain-associated negative affect is more pronounced when pain is localized in the left side of the body. It has been suggested that such side bias results from cortical function lateralization. It is not known, however, if other pain-associated behavioral changes are differentially affected by left- and right-sided pain. To test this hypothesis, the performance of rats with a unilateral spared nerve injury neuropathy installed in the left (SNI-L) or in the right (SNI-R) side was compared in anxiety (elevated-plus maze) and cognitive (spatial working and reference memory, attentional set-shifting task, and delay-to-signal impulsivity task) behavioral paradigms. Results show that SNI-L animals presented an increased anxiety-like profile while maintaining preserved cognitive function. On the contrary, SNI-R animals presented cognitive deficits in all tasks except in the reference memory, but displayed a normal anxiety-like profile. Our results show that left- and right-sided neuropathic pain differentially affects emotional behavior, which is in accordance with previous observations in human subjects, both in experimentally induced pain and in chronic pain conditions. Additionally, our results demonstrate that the cognitive function deterioration associated with unilateral neuropathic chronic pain conditions is also differentially affected.
\end{abstract}

(c) 2012 International Association for the Study of Pain. Published by Elsevier B.V. All rights reserved.

\section{Introduction}

Emotional disturbances and cognitive impairments are a common feature of prolonged pain conditions [61]. These pain-induced behavioral alterations are associated with structural and functional changes in several brain regions [53]. However, the prefrontal cortex (PFC) emerges as one of the most affected brain centers because it has been consistently shown to present morphological and functional alterations in patients with chronic pain syndromes $[1,25,53]$. This region is involved in the modulation of emotional behavior [87] and in a wide range of cognitive functions [59], including working memory, attention, impulsivity, and the construction of flexible adaptive behaviors [59], collectively named executive functions, therefore appearing as a good candidate to mediate the abovementioned effects.

The PFC is the only cortical area that receives direct projections from the spinal cord [46], which might explain its selective vulner-

\footnotetext{
* Corresponding author. Address: School of Health Sciences, University of Minho, Campus de Gualtar, 4710-057 Braga, Portugal. Tel.: +351 253 604808; fax: +351253 604809.

E-mail address: aalmeida@ecsaude.uminho.pt (A. Almeida).

URL: http://www.icvs.uminho.pt/neurosciences/default.aspx (A. Almeida).
}

ability to the effects of prolonged pain. In fact, it has been shown that the thalamus, which also receives spinal cord projections, is similarly affected upon prolonged pain [1], supporting this view. If the plasticity observed in cortical and subcortical areas in chronic pain conditions relates totally or partially with a disturbance of the ascending pathways, we can postulate that lateralized pain would have a differential behavioral impact according to its left/right origin. In fact, the PFC itself has been shown to be functionally lateralized [15]. Additionally, a small number of human studies demonstrated an increased negative effect of left-sided pain $[24,66,77,79]$, but none has studied a lateralized effect on cognitive performance.

To test this hypothesis, we assessed the behavior of young Wistar-Han rats after 1 month of either left- or right-sided neuropathic pain (spared nerve injury (SNI) model [20]) on a battery of tests for sensory, emotional, and cognitive functions.

\section{Methods}

\subsection{Animals and surgery}

Two-month-old male Wistar-Han rats (Charles River Laboratories, Barcelona, Spain) were used in all experiments (Table 1). 
Animals were kept in a room with controlled temperature $\left(22^{\circ} \mathrm{C} \pm 1{ }^{\circ} \mathrm{C}\right)$, 12 -hour light/dark cycle (lights on at $\left.8 \mathrm{am}\right)$, and housed in groups of 2 to 3 animals in plastic cages with food and water available ad libitum. All procedures with animals were approved by the respective local organizations, and the experiments were performed according to the guidelines of the European Communities Council Directive 2010/63/EU.

The SNI model of peripheral neuropathy [20] was used in all experiments. Animals were deeply anesthetized with mixture of 1.5:1.0 of ketamine (Imalgene, $100 \mathrm{mg} / \mathrm{mL}$ - Merial, Lyon, France)/ medetomidine (Dormitor, $1 \mathrm{mg} / \mathrm{mL}$-Orion Pharma, Espoo, Finland) at a dose of $1 \mathrm{~mL} / \mathrm{kg}$. The unilateral ligation and distal axotomy of the tibial and common peroneal nerves on the left (SNI-L) or right (SNI-R) hindpaws was performed as described in detail elsewhere [20]. Briefly, the skin of the lateral surface of the thigh was incised and a longitudinal section was made directly through the biceps femoris muscle exposing the sciatic nerve and its 3 terminal branches. After ligation and removal of 2 to $4 \mathrm{~mm}$ of the distal nerve stumps of the tibial and common peroneal nerves (the sural nerve was left intact), muscle and skin were closed in 2 layers. Sham-operated animals underwent identical surgical procedures (half of the group in the left and the remaining in the right paw) except that tibial and common peroneal nerves were left intact. After the surgery, animals were allowed to recover before the actual testing that was performed, 1 month after the operation. Details on the organization of the behavioral paradigms are given on Table 1.

Animals participating in the conditioned place preference (CPP) experiment had, additionally, an intrathecal catheter for drug delivery to the spinal cord. The catheter (Intramedic PE-10, Becton Dickinson, Sparks, MD) was placed at the spinal cord lumbar level under pentobarbital anesthesia $(50 \mathrm{mg} / \mathrm{kg}$ intraperitoneally) 1 week before actual testing, as described in detail elsewhere [86]. After recovery from anesthesia, the correct placing of the catheter was verified by injecting lidocaine $(4 \%, 7$ to $10 \mu \mathrm{L}$ followed by $10 \mu \mathrm{L}$ of saline for flushing) with a $50-\mu \mathrm{L}$ Hamilton syringe (Hamilton Company, Bonaduz, Switzerland). Only those rats that had no motor impairment before lidocaine injection but had a bilateral paralysis of hind limbs after intrathecal administration of lidocaine were studied further.

All behavioral experiments were performed during the light period of the daily cycle. Acclimatization to the testing room was allowed for approximately 1 hour. To avoid possible bias, in particular related to the testing period, animals belonging to different groups were tested alternately.

\subsection{Pain assessment}

\subsubsection{Von Frey monofilaments}

Development of neuropathic hypersensitivity was verified in all animals. In the group undergoing CPP, this was done in the

Table 1

Organization and distribution of the experimental groups.

\begin{tabular}{lllllll}
\hline Group & N & Von Frey/CPP & EPM & MWM/WM & ASST & Impulse control \\
\hline 1 & 18 & X & - & - & - & - \\
2 & 23 & - & X & - & X & - \\
3 & 24 & - & X & - & - & X \\
4 & 27 & - & - & X & X & - \\
5 & 25 & - & - & X & - & -
\end{tabular}

To avoid repetition interferences, a maximum of 2 behavioral assays were carried out in each group of animals. Except for group 1, all animals were tested for allodynia using von Frey monofilaments at the end of the behavioral proceedings to minimize the distress associated with the pain test. Group 1 was used exclusively to assess laterality-related differences in evoked and ongoing pain (see text). ASST = attentional set-shifting test; $C P P=$ conditioned place preference; $E P M=$ elevated-plus maze; $\mathrm{MWM}=$ spatial reference Morris water maze; $\mathrm{WM}=$ spatial reference working memory. beginning before the installation of the intrathecal catheter and was used to compare the lesion lateralization, hypersensitivity was assessed 1 week after the end of emotional/cognitive behavioral assessment to verify the successful development and maintenance of the neuropathy. Animals were habituated to the experimental conditions 1 to 2 hours daily for 2 to 3 days. For assessment of tactile allodynia, the hind limb withdrawal threshold was determined by stimulating the sural nerve areas in the hind paw of the nerve-injured or sham-operated limb with monofilaments. The calibrated series of monofilaments used in this study produced forces ranging from 0.008 to $60 \mathrm{~g}$ (North Coast Medical Inc., Morgan Hill, CA). The monofilaments were applied to the lateral foot pad with increasing force until the rat withdrew its hind limb. The lowest force producing a withdrawal response was considered the threshold. The threshold for each hind paw of each rat was based on 3 separate measurements, and the median of these values was considered to represent the threshold. Limb withdrawal threshold was assessed in a separate session 1 month after nerve injury or sham operation.

\subsection{2. $C P P$}

For analysis of ongoing pain 1 month after the nerve injury or sham operation, rats received spinal clonidine hydrochloride $(\alpha-2$ adrenoceptor agonist, Sigma-Aldrich, St. Louis, MO) as previously described for a single conditioning trial protocol [40]. Animals were tested in automated CPP apparatuses (Place Preference System, San Diego Instruments Inc., San Diego, CA) that recorded their movement/location in each chamber using a computer-controlled $4 \times 16$ array of photobeams. All rats were habituated to the apparatus with 3 daily sessions, during which they had access to all 3 chambers (days 1 and 2: $30 \mathrm{~min} / \mathrm{session}$, day 3: $15 \mathrm{~min} / \mathrm{session}$ ). Rats that spent more than 720 seconds in one of the conditioning chambers on day 3 were eliminated from the study. The following day (day 4 ), all rats received a morning injection of saline and were immediately placed in one of the pairing chambers for 30 minutes. Four hours later, all rats received clonidine and were immediately placed in the opposite chamber for 30 minutes. Clonidine was administered intrathecally at the dose of $10 \mu \mathrm{g} / 10 \mu \mathrm{L}$ and was flushed with $10 \mu \mathrm{L}$ of saline. Clonidine and saline control injections were monitored by movement of an air bubble between the drug/saline control and the saline used for flushing. At 20 hours after drug pairing (day 5), animals were placed drug-free in the CPP boxes with access to all chambers. The amount of time spent in each of the 2 chambers (salineand drug-paired) was automatically registered and used to quantify the analgesia conditioning effect.

\subsection{Anxiety-like behavior}

The elevated plus-maze (EPM) was performed in a plus-shaped maze made on black polypropylene plastic, with 2 opposed open arms $(50.8 \times 10.2 \mathrm{~cm})$ and 2 opposed closed arms with the same dimensions but surrounded by walls ( $40.6 \mathrm{~cm}$ height, Med Associates Inc., St. Albans, VT). The whole structure was elevated $72.4 \mathrm{~cm}$ from the floor and was surrounded by 4 black walls perpendicular and at equal distances from each arm of the maze. Animals were placed at the centre of the maze and allowed to explore for 5 minutes. At the end of each trial, all areas were cleaned with $10 \%$ alcohol and carefully dried. The number of arm entries and the time spent in each arm was registered. The percentage of the time spent in the open arms is inversely related with anxiety-like behavior. The number of closed-arm entries was used as an index of locomotor activity.

\subsection{Paradigms of cognitive behavior}

\subsubsection{Working and reference memory tasks}

Working memory (WM) and spatial reference memory (Morris water maze, MWM) tests were performed in a circular tank (diam- 
eter $170 \mathrm{~cm}$ ) with black walls located in the center of a room with white walls where black geometric figures had been placed as spatial references. A video camera positioned in the ceiling captured the image to a video tracking system (Viewpoint, Champagne au Mont d'Or, France). A black, circular (diameter $12 \mathrm{~cm}$ ) platform was placed within one of the quadrants virtually assigned in the computer. During the tests, the water temperature was kept in the range of $22^{\circ} \mathrm{C}$ to $24^{\circ} \mathrm{C}$ and the level was such that it slightly covered the platform (therefore, invisible to the rats). In the beginning of each trial the animal was placed in the respective quadrant (Table 2) facing the maze walls. The trial was interrupted if the platform was found or if 120 seconds had elapsed (thereafter the animal was guided to the target). The animal was then allowed to spend 30 seconds on the platform before starting a new trial. In the WM paradigm, the daily trial-to-trial progression of the swim distance was averaged for the different platform locations, whereas in the MWM, day-to-day progression (learning) was averaged across the 4 daily trials for the same platform location.

\subsubsection{Attentional set-shifting task}

In the attentional set-shifting task (ASST) [7], animals are required to find rewards hidden in 1 of 2 bowls, according to a series of rules involving 2 different stimuli sets, textures and odors, that are simultaneously presented. On each rule, only stimuli in 1 category are relevant for finding the reward (see Table 3 for a general description of the rules and Supplemental Table 1 for more detailed information). Because rules change throughout the task (4 rules with odor as the relevant stimulus set, 4 rules with texture as the relevant stimulus set), the animal is prompted to shift its attention from one set to the other, hence the name of the test. The ASST apparatus is a rectangular arena $(40 \times 70 \mathrm{~cm})$, made of black acrylic, with 20-cm-high walls, and near one of its extremities, 2 bowls ( $7 \mathrm{~cm}$ diameter $/ 4 \mathrm{~cm}$ depth) side by side, buried with their upper limit at floor level and filled with digging media (sawdust); an immovable wall separated the areas containing each bowl to prevent an animal from quickly moving from one to the other. Textures were attached to the floor of the arena, at the entrance of the area containing each bowl, whereas odors were presented by rubbing the edge of the bowls with cotton embedded in concentrated aromatic oils; to preventing fading, odor was renewed every 10 trials or whenever there was a rule change.

Six days before the beginning and throughout the experimental period, food availability was restricted to the last hour of the day cycle, with the weight of the animals being maintained between $85 \%$ and $90 \%$ of free feeding values. During this period, 2 pieces of Cheerios (Nestle, Portugal) per animal were given to the animals in their cages. In addition, in the last 3 days before the experiment, animals were placed in the apparatus and accustomed to dig in

Table 2

Sequence and organization of the spatial reference WM and MWM tests.

\begin{tabular}{lllllll}
\hline Day & Platform location & Protocol & \multicolumn{4}{l}{ Starting quadrant } \\
\cline { 4 - 7 } & & & T1 & T2 & T3 & T4 \\
\hline 1 & W & WM & N & S & W & E \\
2 & N & WM & W & N & S & E \\
3 & E & WM & E & S & N & W \\
4 & S & WM/MWM & E & W & N & S \\
5 & S & MWM & N & S & E & O \\
6 & S & MWM & S & N & O & E \\
7 & S & MWM & O & E & S & N
\end{tabular}

Platform location on each day and the starting quadrant for each trial are given. Note that when the animal initiates the trial in the quadrant where the platform is located (bold), there is an increased chance of finding the platform by accident. To avoid this possible bias, these trials were distributed evenly in the 4 days. $\mathrm{MWM}=$ spatial reference Morris water maze; $\mathrm{WM}=$ spatial reference working memory.
Table 3

Attentional set-shifting task (ASST) sequence.

\begin{tabular}{|c|c|c|c|c|}
\hline \multirow[t]{2}{*}{ Step } & \multicolumn{2}{|c|}{ Dimensions } & \multicolumn{2}{|l|}{ Combinations } \\
\hline & Odor & Texture & Correct & Incorrect \\
\hline $\mathrm{SD}_{\text {odo }}$ & Relevant & - & $\mathbf{O}_{1} /-$ & $\mathrm{O}_{2} /-$ \\
\hline $\mathrm{SD}_{\text {tex }}$ & - & Relevant & $-/ \mathbf{T}_{1}$ & $-/ \mathrm{T}_{2}$ \\
\hline$C D$ & Relevant & Irrelevant & $\mathbf{O}_{3} / \mathrm{T}_{3}$ (or 4 ) & $\mathrm{O}_{4} / \mathrm{T}_{4 \text { (or } 3 \text { ) }}$ \\
\hline $\operatorname{Rev}_{1}$ & Relevant & Irrelevant & $\mathbf{O}_{\mathbf{4}} / \mathrm{T}_{3}$ (or 4 ) & $\mathrm{O}_{3} / \mathrm{T}_{4 \text { (or } 3 \text { ) }}$ \\
\hline $\mathrm{IDS}_{1}$ & Relevant & Irrelevant & $\mathbf{O}_{\mathbf{5}} / \mathrm{T}_{5 \text { (or } 6 \text { ) }}$ & $\mathrm{O}_{6} / \mathrm{T}_{6 \text { (or } 5 \text { ) }}$ \\
\hline $\operatorname{Rev}_{2}$ & Relevant & Irrelevant & $\mathbf{0}_{6} / \mathrm{T}_{5}$ (or 6 ) & $\mathrm{O}_{5} / \mathrm{T}_{6 \text { (or } 5 \text { ) }}$ \\
\hline EDS & Irrelevant & Relevant & $\mathrm{O}_{7 \text { (or } 8 \text { ) }} / \mathbf{T}_{\mathbf{7}}$ & $\mathrm{O}_{8 \text { (or } 7 \text { ) }} / \mathrm{T}_{8}$ \\
\hline $\operatorname{Rev}_{3}$ & Irrelevant & Relevant & $\mathrm{O}_{7 \text { (or 8) }} / \mathbf{T}_{\mathbf{8}}$ & $\mathrm{O}_{8 \text { (or } 7)} / \mathrm{T}_{7}$ \\
\hline $\mathrm{IDS}_{2}$ & Irrelevant & Relevant & $\mathrm{O}_{9 \text { (or 10) }} / \mathbf{T}_{\mathbf{9}}$ & $\mathrm{O}_{10 \text { (or } 9)} / \mathrm{T}_{10}$ \\
\hline $\operatorname{Rev}_{4}$ & Irrelevant & Relevant & $\mathrm{O}_{9 \text { (or 10) }} / \mathbf{T}_{\mathbf{1 0}}$ & $\mathrm{O}_{10 \text { (or } 9)} / \mathrm{T}_{9}$ \\
\hline
\end{tabular}

Simple ( $\mathrm{SD}_{\text {odo }}$ and $\left.\mathrm{SD}_{\text {tex }}\right)$ and compound (CD, $\operatorname{Rev}_{1-4}, \mathrm{IDS}_{1-2}$, and $\left.\mathrm{EDS}\right)$ presentations were performed in 2 different and sequential days. In the first, only 1 perceptual dimension (odor or texture) was present at each time, whereas in the second, both dimensions, whether or not relevant to located the reward, were present. The organization of the presentations on each trial is detailed in Supplemental Table 1. ASST $=$ attentional set-shifting task; $C D=$ compound discrimination; EDS = extradimensional shift; IDS = intradimensional shift; $\mathrm{O}=$ odor; $\mathrm{Rev}=$ reversal; $\mathrm{SD}=$ simple discrimination; $\mathrm{T}=$ texture.

both bowls by burying progressively deeper Cheerios in the digging media. In the first experimental day animals were presented only with odors (first rule) or textures (second rule), whereas on the second day both sets of stimuli were always present in a total of 8 rules (see Table 3 for a general description); presentation of different rules was separated by a 10-minute interval, during which animals returned to their home cages. Each trial was initiated by lifting a removable barrier, allowing the animal to exit the waiting area (located in the side opposite to the bowls), and terminated when the animal dug vigorously in the media in one of the bowls. A performance criterion of 6 consecutive correct trials was adopted for each rule throughout the test, with the number of trials necessary to reach such criteria used as the main performance measure. Of note, the combination odor/texture and its association with the left/right bowl varied in each trial according to a pre-established order (see detailed information in Supplemental Table 1).

\subsubsection{Inhibitory control to variable delay}

This task was performed in the classical 5-choice serial reaction time task apparatus [4], consisting of a nearly squared arena with 20 -cm-high walls, one being curved and having 5 apertures at the animal head level with nose-poke detectors and a light. In the opposite wall, a single aperture with similar dimensions is connected to a food dispenser. In this test, only the middle aperture out of the 5 nose-poke apertures was available (the remaining 4 were closed). The day before the first session, food was removed from animals' cages, and from then on its availability was restricted to the last hour of the light cycle. Animals were trained to nose-poke the open aperture to receive a sugar pellet (dustless precision pellets, Bio-Serv, Frenchtown, NJ). Each trial in the training sessions started with the house-light on, signaling an ongoing trial. After a 3-second delay interval, the light-signaling aperture lit up. A nose poke before the signal (impulsive response) interrupted the trial and initiated a "punishment" period of 5 seconds (house-light off). On the other hand, a nose poke after the signal triggered a pellet delivery. Each training session spanned 30 minutes or 100 trials. After 9 training sessions all animals were able to accomplish 100 trials, and except for 2 (1 sham and one SNI$\mathrm{L})$, had $<30 \%$ of impulsive responses. In the 10 th session, animals were tested in a sequence of 25 trials at a 3-second delay, followed by 70 trials at a 7- or 10-second delay attributed randomly by the computer and returning finally to a 3-second delay for 25 additional trials. In this session, premature responses were not 
punished. The total number of premature responses per total amount of delay time was used to compare groups' performances.

\subsection{Statistics}

The data are presented as mean \pm SEM and analyzed using 1 - or 2-way analysis of variance, with repeated measures when appropriate, followed by a Tukey post-hoc test for multiple comparisons (comparison of 3 or more groups), or $t$ test (comparison of 2 groups). $P<.05$ was considered to represent a significant difference.

\section{Results}

\subsection{Pain measurements}

Using established paradigms to assess acute evoked (von Frey monofilaments) and ongoing nonprovoked pain (analgesia-derived conditioned place-preference) [40], we firstly showed that 1 month after the installation of the SNI model, SNI-L and SNI-R neuropathies have similar algogenic properties. Both right and left sham-operated animals were used as control subjects, but their performances were clustered together because there were no differences between them. Nerve-injured animals presented an expected decrease of the monofilament-induced limb withdrawal threshold $\left(F_{2,13}=25.98, P<.0001\right)$, which was of similar magnitude irrespective of lesion side (Fig. 1A).

In the $\mathrm{CPP}$, before clonidine-derived conditioning, animals failed to show a preference for any of the chambers $\left(F_{1,26}=0.45, P=.51\right.$, Fig. 1B), independent of the experimental group $\left(F_{2,26}=0.24\right.$, $P=.79$ ). However, a single intrathecal injection of clonidine at the dose of $10 \mu \mathrm{g}$ produced a significant place-preference for the clonidine-paired chamber $\left(F_{1,26}=9.03, P=.0058\right.$, Fig. $\left.1 C\right)$ and the clonidine-induced place-preference varied with the experimental group $\left(F_{2,26}=3.54, P=.044\right)$. Post hoc testing indicates that the clonidine-induced place-preference was observed only in SNI animals but not in sham-operated ones (Fig. 1C). Moreover, the clonidineinduced place-preference was of equal magnitude in the SNI-L and SNI-R groups.

\subsection{Anxiety-like behavior}

Because increased anxiety is frequently reported in both humans with prolonged pain conditions and animal models of chronic pain, we assessed anxiety-like behavior, in a different cohort of animals, in the EPM. We observed an effect of the neuropathy side in the percent of time spent in the EPM openarms $\left(F_{2,37}=3.888, P=.03\right.$, Fig. $\left.2 A\right)$. SNI-L animals spent significantly less time when compared with both SNI-R and sham-lesioned animals $(P=.05$ in both comparisons). The number of closed arms entries, an index of locomotor activity, was similar in all groups $\left(F_{2,37}=1.640, P=.21\right.$, Fig. $\left.2 B\right)$, indicating that the differences observed in openarms were specifically related with SNI-L anxiogenic properties and not with a locomotor impairment caused by the lesion.

\subsection{Cognitive performance}

Repeated-measures analysis of the trial-to-trial efficiency gain in the water maze revealed a statistically significant impact of the lesion $\left(F_{2,48}=4.987, P=.01\right)$, with SNI-R performing significantly worse than both sham $(P=.01)$ and SNI-L $(P=.04)$ in the WM test (Fig. 3A). On the contrary, the daily efficiency gain on the spatial reference memory task, MWM, is not affected by the experimental condition $\left(F_{2,48}=1.628, P=.21\right.$, Fig. $\left.3 B\right)$.

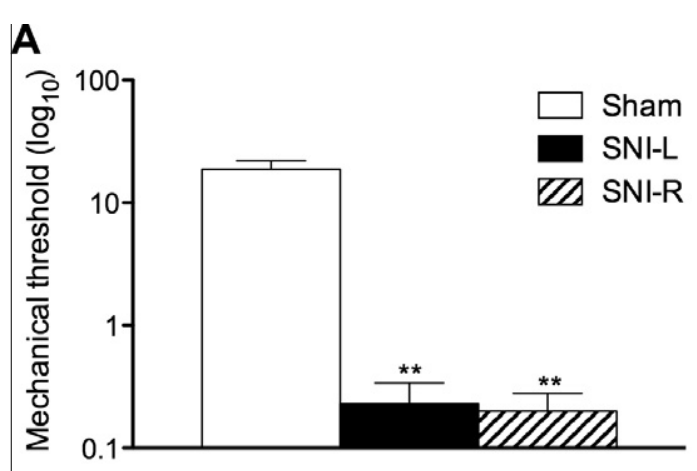

B
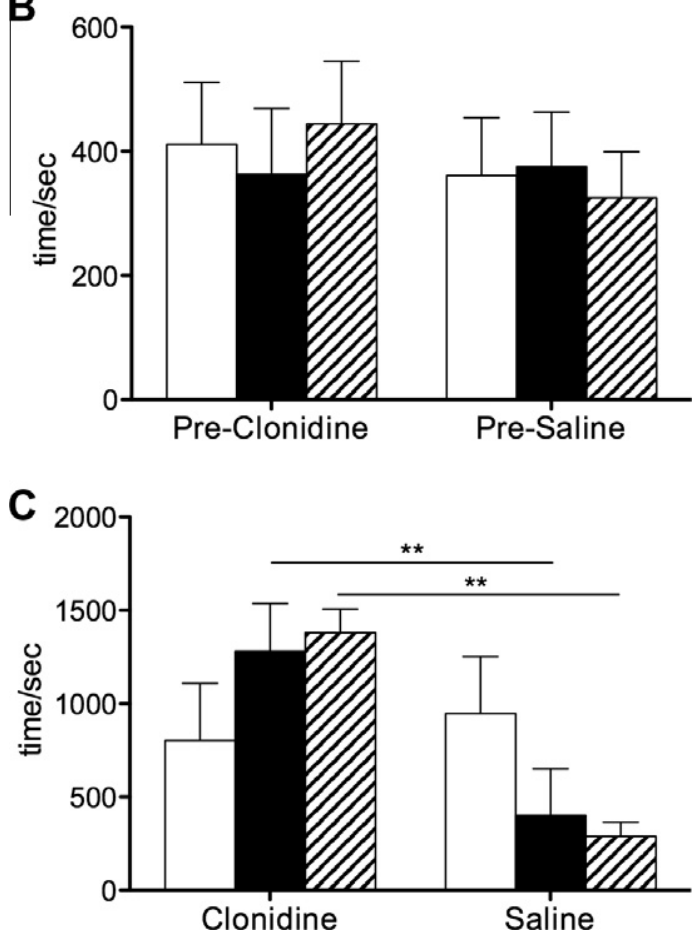

Fig. 1. Measures of evoked (Von Frey) and ongoing (conditioned place preference) pain in the SNI model of neuropathic pain. Nerve injury produced a significant decrease in the monofilament-induced limb withdrawal threshold, whereas the side of nerve injury had no significant effect on the withdrawal threshold (A). Contralateral to the SNI, the threshold did not differ from that of sham-operated control (not show). During the preconditioning period of the conditioned place preference, animals failed to show preference for any of the chambers independent of the experimental group (B); clonidine treatment, however, produced a significant place preference for the clonidine-paired chamber in SNI animals independent of the injury side (C). Note that total testing times were different in (B) (15 minutes) and $(C)$ (30 minutes), because of which the scales of their $\mathrm{Y}$ axes are different. ${ }^{* *} P<.01$. Data presented as mean \pm SEM.SNI $=$ spared nerve injury; SNI-L $=$ left spared nerve injury; SNI-R right spared nerve injury.

Similarly, the side of the SNI lesion had a significant effect on the ASST reversal (Rev) steps 1 to 4 (Rev $1-F_{2,45}=14.522$, $P<.001$, Rev $2-\mathrm{F}_{2,45}=11.347, P<.001$, Rev $3-\mathrm{F}_{2,45}=46.343$, $P<.001$, Rev $4-F_{2,45}=24.661, P<.001$, Fig. 4). In these cases, SNI-R animals required a significantly higher number of trials to reach the criteria than sham and SNI-L animals $(P<.001$ in all comparisons) to accomplish the task. No differences were found between groups in the other task steps, particularly in the extradimensional shift $\left(F_{2,45}=2.949, P=.063\right.$, Fig. 4$)$.

Finally, in the delay-to-signal task, no differences were found between groups concerning the absolute number of impulsive responses at 3, 7 , and 10 seconds delay (Fig. 5A). However, the variation $(\triangle)$ to baseline differed significantly at 10 seconds delay 

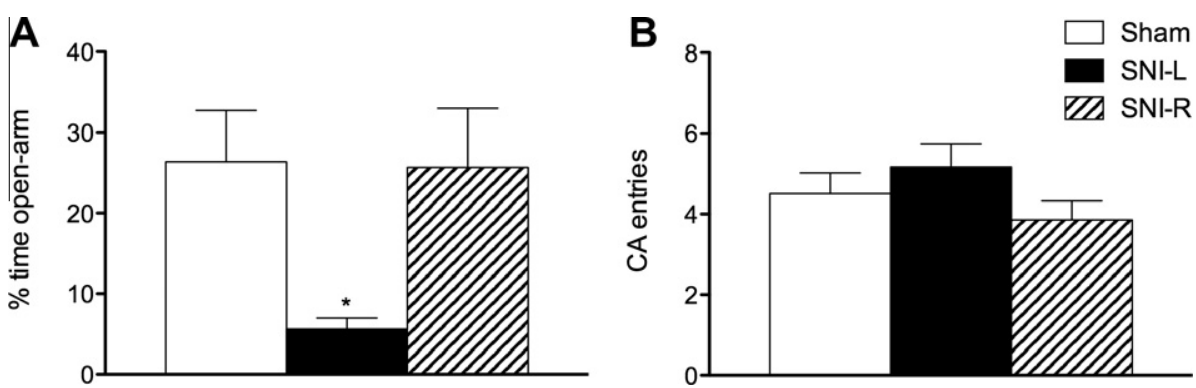

Fig. 2. Anxiety-like behavior in the EPM. Left- but not right-sided spared nerve injury animals presented a decreased percentage of time spent in the EPM openarms, indicating anxiety-like behavior $(A)$. This result cannot be attributed to differences in the locomotor behavior because neither left-sided nor right-sided spared nerve injury influenced the number of EPM closed armentries $(B) .{ }^{*} P<.05$. Data presented as mean \pm SEM. EPM = elevated-plus maze. CA $=\mathrm{xxx}$; SNI-L = left spared nerve injury; SNI-R right spared nerve injury.
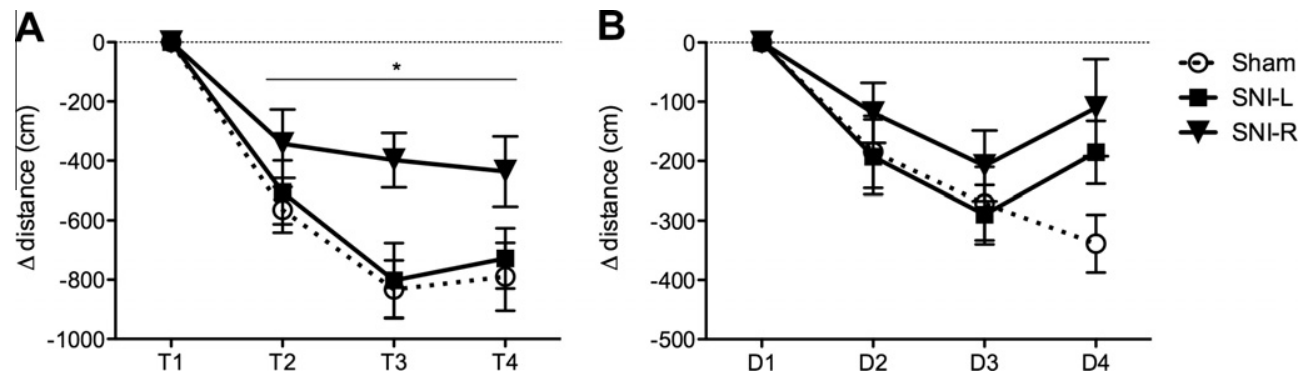

Fig. 3. Working memory and spatial reference memory. In the working memory paradigm (A), the side of the SNI had an impact on animals' performance with the SNI-R group performing significantly worse than both sham and SNI-L groups. In the spatial reference memory group (B), however, SNI had no effect on the ability to learn the platform location. ${ }^{*} P<.05$. Data presented as mean \pm SEM. $D_{1-4}=$ day 1 to 4 ; SNI = spared nerve injury; SNI-L = left spared nerve injury; SNI-R right spared nerve injury; $T_{1-}$ $4=$ trial 1 to 4

$\left(F_{2,21}=7.884, P=.003\right.$, Fig. $\left.5 B\right)$, namely SNI-R presented close to 6 times more impulsive responses, twice the value presented by sham $(P=.01)$ and SNI-L $(P=.007)$ animals.

\section{Discussion}

Aside from sensory abnormalities (e.g., hyperalgesia and allodynia) that are considered to be hallmarks of neuropathies $[45,61]$, rodent models of neuropathic pain proved to be robust enough to manifest a whole range of emotional and cognitive

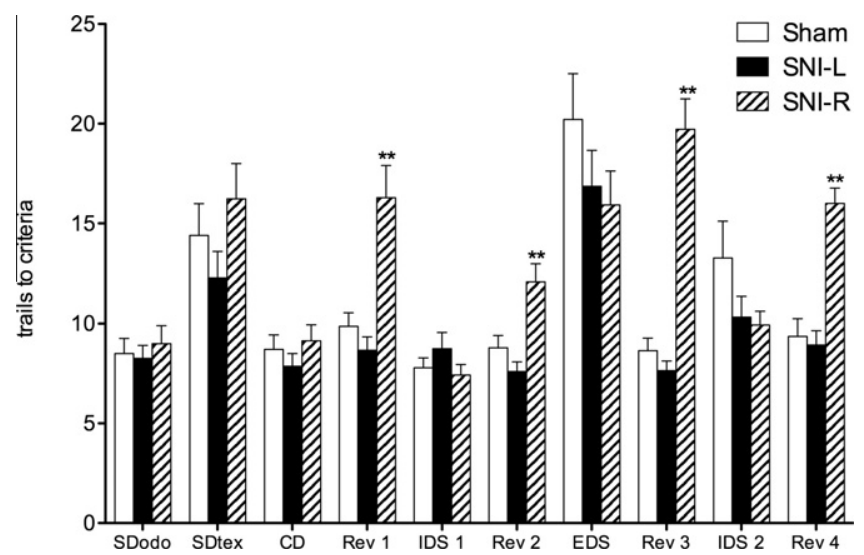

Fig. 4. Attentional set-shifting task. SNI-R animals required a significantly higher number of trials to criteria than sham and SNI-L animals to accomplish the reversal $\left(\operatorname{Rev}_{1-4}\right)$ steps of the attentional set-shifting task. No differences were found between groups in the other task steps, simple discrimination (odor, $\mathrm{SD}_{\text {odo }}$ and texture, $\mathrm{SD}_{\text {tex }}$ ), compound discrimination (CD), intradimensional shift (IDS 1-2), and extradimensional shift (EDS). ${ }^{* *} P<.001$. Data presented as mean \pm SEM. SNI-L $=$ left spared nerve injury; SNI-R right spared nerve injury. disturbances that have also been observed in the human disease. In the present study we confirmed that indeed SNI animals manifest a deterioration of emotional behavior and poorer cognitive performances, and additionally, that such effects depended on the side of peripheral nerve injury. Left-sided lesions were detrimental to emotional behavior, whereas right-sided lesions affected cognitive performance, particularly in PFC-dependent tasks.

A small number of studies in human volunteers addressed in the past a putative differential impact of left-/right-sided pain on emotional arousal $[24,66,77,79]$. It was demonstrated that leftsided pain was more distressful and emotionally disruptive than similar right-sided painful conditions. Our finding that left-sided but not right-sided SNI lesioned rats displayed a hyperanxious phenotype is therefore in line with these observations. Other animal studies, using left-sided [33,34,43,71,72,88-91] or right-sided $[5,28,41,52,62,63,94]$ pain diverge, however, in their results concerning pain-related anxiogenic effect. A number of factors can reasonably explain the disparate findings, including differences in the pain model, experimental organization (some investigators report pain tests immediately before anxiety assessment), and pain duration. In what concerns the latter, it has been demonstrated that anxiety-like manifestations emerge only about 4 weeks after pain onset [88,94], which is in accordance with the temporal frame of our analyses. Importantly, none of these studies compared the impact of left- and right-sided pain under the same experimental conditions.

The detrimental effect of prolonged pain on cognitive function was also addressed in the past by a small number of studies using experimental models of chronic pain [12,36,41,45,47,57,64,65,68] (see also Moriarty et al. for review [61]). Again, none of these studies compared the differential effect of left- and right-sided pain on cognitive performance. We assessed animals' performance in several PFC-dependent executive functions, including WM (assessed in the water maze), behavioral flexibility (assessed in an ASST), 

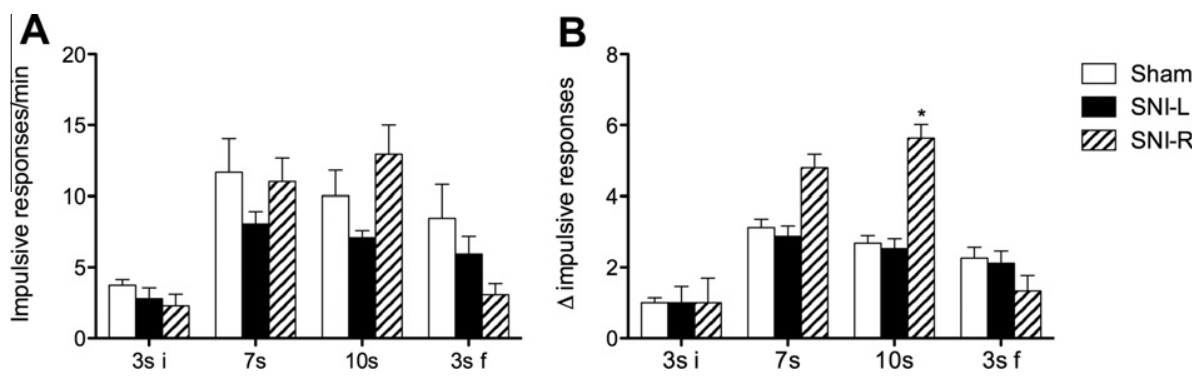

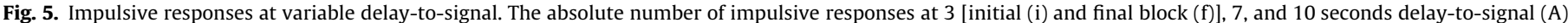

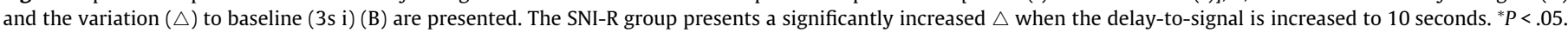
Data presented as mean \pm SEM. SNI-L = left spared nerve injury; SNI-R right spared nerve injury.

and impulse control $[18,21,58,69,76]$, because it has been consistently demonstrated that PFC presents robust morphological and functional alterations in prolonged pain conditions both in humans $[1,19,25,26,29,39,44,49,53,60,70,81,84]$ and rats [56,83]. Results from our cognitive multimodal analyses confirmed that PFCdependent domains are affected in chronic pain conditions, particularly when lesions are right-sided (SNI-R). These are generally in agreement with previously reported observations, although some inconsistencies have been detected, probably due to differences inherent to the cognitive paradigms used. The work of Renet al. is amenable for comparison because they used the same neuropathy model (installed on the left side, SNI-L), for a similar amount of time (cognitive tests at 11 to 20 and 31 to 40 postsurgery days) [68]. In their study, and contrary to our observations, SNI-L presented deficits in a WM task performed in an 8-arm radial mazetest. This discrepancy is most probably due to the different nature of the water maze and 8-arm paradigms. In both cases, animals can adopt strategies unrelated to WM (e.g., stereotyped search), reinforcing the importance of a multimodal behavioral approach [23]. In a different study, Hu et al. tested rats with a left-sided neuropathy (spinal nerve lesion model, SNL-L) of 30 days' duration in the MWM [36]. The learning curves of SNL-L and control animals had a similar slope, suggesting that pain has no effect on long-term spatial reference memory, which is in agreement with our results [36]. Concerning impulsive behavior, our results are in agreement with those obtained by Pais-Vieira et al., who evaluated the performance of rats with a left-sided monoarthritis in a 5-choice serial reaction time task paradigm [64].

The behavioral domains affected in SNI animals support the idea that PFC-dependent functions are particularly susceptible in chronic pain conditions. The fact that the behavioral performance of the SNI-R in the ASST task was specifically impaired in the reversal but not in the extradimensional shift steps further suggests that PFC malfunction is restricted to the medial/orbital PFC ( $\mathrm{mPFC} / \mathrm{OFC}$ ) while sparing dorsomedialprelimbic and cingulate PFC $[7,8,22]$. Experimental evidence is still needed to confirm this hypothesis. However, data obtained by others may be considered in this context. Firstly, the mPFC/OFC are the only cortical areas where direct projections from the contralateral spinal cord dorsal horn terminate (reviewed by Lima [46]). Secondly, manipulations of ventral $\mathrm{mPFC} / \mathrm{OFC}$ subareas have been shown to influence behavioral outcomes in anxiety paradigms and the levels of anxiety-related biomarkers such as corticosteroids. Importantly, this effect is lateralized, depending exclusively on the right PFC, expectably the area affected in SNI-L (reviewed by Sullivan and Gratton [87]). Finally, Luerding et al. found in fibromyalgia patients an impairment on nonverbal working memory that was positively correlated with the grey matter volume of the left middle frontal gyrus [49]. It should, however, be acknowledged that the distinctive features of the left/right mPFC contribution to cognitive construction are still a matter of debate [15], and factors such as age must be considered. For instance, older subjects frequently present bilateral PFC activity in tasks that are associated with unilateral PFC activation in young subjects [6,75]. This phenomenon probably underlies the cognitive deficits observed in mid-aged SNI-L animals shown by our group in a previous study [45].

It has long been a matter of dispute whether some pain-related phenomena occur with a lateralization bias. Among them are pain frequency $[13,30,31,51,55]$, threshold $[2,3,9,16,27,32,37,48,50,54$, $66,67,73,74,77-79,82,85,92,93]$, changes in central processing and/or plasticity $[10,11,14,17,35,38,42,80]$, and emotional charge $[24,66,77,79]$. Our data support the proposal that left- and rightsided neuropathic pain differentially impact on emotional behavior. Additionally, our data demonstrate that the side-dependent effect extends to cognitive domains. Measurements of both evoked and ongoing pain-related behaviors presented no differences between SNI-L and SNI-R, and therefore do not differ between the SNI groups. Altogether, the body of evidence presented strongly supports our initial hypothesis that peripheral nerve injury results in functional impairments that depend on the cortical termination sites of the ascending pathways mediating the injury discharge. Morphofunctional studies centered in the PFC must be carried out in the future to clarify this possibility.

\section{Conflict of interest statement}

None of the authors report a conflict of interest.

\section{Acknowledgements}

This work was funded by the Portuguese Science Foundation Project PTDC/SAU-NEU/108557/2008, COMPETE and FEDER, and Grant SFRH/BD/29166/2006.

\section{Appendix A. Supplementary data}

Supplementary data associated with this article can be found, in the online version, at http://dx.doi.org/10.1016/j.pain.2012.07.007.

\section{References}

[1] Apkarian AV, Sosa Y, Sonty S, Levy RM, Harden RN, Parrish TB, Gitelman DR. Chronic back pain is associated with decreased prefrontal and thalamic gray matter density. J Neurosci 2004;24:10410-5.

[2] Bar KJ, Brehm S, Boettger MK, Boettger S, Wagner G, Sauer H. Pain perception in major depression depends on pain modality. PAIN ${ }^{\circledR} 2005 ; 117: 97-103$.

[3] Bar KJ, Greiner W, Letsch A, Kobele R, Sauer H. Influence of gender and hemispheric lateralization on heat pain perception in major depression. J Psychiatr Res 2003;37:345-53.

[4] Bari A, Dalley JW, Robbins TW. The application of the 5-choice serial reaction time task for the assessment of visual attentional processes and impulse control in rats. Nat Protoc 2008;3:759-67.

[5] Benbouzid M, Pallage V, Rajalu M, Waltisperger E, Doridot S, Poisbeau P, Freund-Mercier MJ, Barrot M. Sciatic nerve cuffing in mice. A model of sustained neuropathic pain. Eur J Pain 2008;12:591-9. 
[6] Bergerbest D, Gabrieli JD, Whitfield-Gabrieli S, Kim H, Stebbins GT, Bennett DA, Fleischman DA. Age-associated reduction of asymmetry in prefrontal function and preservation of conceptual repetition priming. Neuroimage 2009;45:237-46.

[7] Birrell JM, Brown VJ. Medial frontal cortex mediates perceptual attentional set shifting in the rat. J Neurosci 2000;20:4320-4.

[8] Bissonette GB, Martins GJ, Franz TM, Harper ES, Schoenbaum G, Powell EM Double dissociation of the effects of medial and orbital prefrontal cortical lesions on attentional and affective shifts in mice. J Neurosci 2008;28:11124-30.

[9] Brennum J, Kjeldsen M, Jensen K, Jensen TS. Measurements of human pressurepain thresholds on fingers and toes. PAIN ${ }^{\circledR} 1989 ; 38: 211-7$

[10] Brooks JC, Nurmikko TJ, Bimson WE, Singh KD, Roberts N. FMRI of thermal pain: effects of stimulus laterality and attention. Neuroimage 2002;15:293-301.

[11] Brugger M, Ettlin DA, Meier M, Keller T, Luechinger R, Barlow A, Palla S, Jancke L, Lutz K. Taking sides with pain-lateralization aspects related to cerebral processing of dental pain. Front Hum Neurosci 2011;5:12.

[12] Cain CK, Francis JM, Plone MA, Emerich DF, Lindner MD. Pain-related disability and effects of chronic morphine in the adjuvant-induced arthritis model of chronic pain. Physiol Behav 1997;62:199-205.

[13] Campbell JA, Lahuerta J, Bowsher D. Pain laterality in relation to site of pain and diagnosis. PAIN ${ }^{\circledR} 1985 ; 23: 61-6$

[14] Carrasquillo Y, Gereau RWT. Hemispheric lateralization of a molecular signal for pain modulation in the amygdala. Mol Pain 2008;4:24

[15] Cerqueira JJ, Almeida OF, Sousa N. The stressed prefrontal cortex. Left? Right! Brain Behav Immun 2008;22:630-8.

[16] Chandramouli R, Kanchan BR, Ambadevi B. Right-left asymmetry in tonic pain perception and its modification by simultaneous contralateral noxious stimulation. Neuropsychologia 1993;31:687-94.

[17] Coghill RC, Gilron I, Iadarola MJ. Hemispheric lateralization of somatosensory processing. J Neurophysiol 2001;85:2602-12.

[18] Dalley JW, Cardinal RN, Robbins TW. Prefrontal executive and cognitive functions in rodents: neural and neurochemical substrates. Neurosci Biobehav Rev 2004;28:771-84.

[19] DaSilva AF, Becerra L, Pendse G, Chizh B, Tully S, Borsook D. Colocalized structural and functional changes in the cortex of patients with trigeminal neuropathic pain. PLoS One 2008;3:e3396.

[20] Decosterd I, Woolf CJ. Spared nerve injury: an animal model of persistent peripheral neuropathic pain. PAIN ${ }^{\circledR} 2000 ; 87: 149-58$.

[21] Diamond A. Biological and social influences on cognitive control processes dependent on prefrontal cortex. Prog Brain Res 2011;189:319-39.

[22] Dias R, Robbins TW, Roberts AC. Dissociation in prefrontal cortex of affective and attentional shifts. Nature 1996;380:69-72.

[23] Dubreuil D, Tixier C, Dutrieux G, Edeline JM. Does the radial arm maze necessarily test spatial memory? Neurobiol Learn Mem 2003;79:109-17.

[24] Gagliese L, Schiff BB, Taylor A. Differential consequences of left- and rightsided chronic pain. Clin J Pain 1995;11:201-7.

[25] Geha PY, Baliki MN, Harden RN, Bauer WR, Parrish TB, Apkarian AV. The brain in chronic CRPS pain: abnormal gray-white matter interactions in emotional and autonomic regions. Neuron 2008;60:570-81.

[26] Gerstner G, Ichesco E, Quintero A, Schmidt-Wilcke T. Changes in regional gray and white matter volume in patients with myofascial-type temporomandibular disorders: a voxel-based morphometry study. J Orofac Pain 2011;25:99-106.

[27] Gobel H, Westphal W. Lateral asymmetry of the human pain sensitivity. Schmerz 1987;1:114-21.

[28] Gonçalves L, Silva R, Pinto-Ribeiro F, Pego JM, Bessa JM, Pertovaara A, Sousa N Almeida A. Neuropathic pain is associated with depressive behaviour and induces neuroplasticity in the amygdala of the rat. Exp Neurol 2008;213:48-56.

[29] Gustin SM, Wrigley PJ, Siddall PJ, Henderson LA. Brain anatomy changes associated with persistent neuropathic pain following spinal cord injury. Cereb Cortex 2010;20:1409-19.

[30] Hall W, Hayward L, Chapman CR. On "the lateralization of pain". PAIN ${ }^{\circledR}$ 1981;10:337-56.

[31] Harness DM, Chase PF. Lateralization of chronic facial pain: fact or fiction. Cranio 1990;8:339-41.

[32] Haslam DR. Lateral dominance in the perception of size and of pain. Q J Exp Psychol 1970;22:503-7.

[33] Hasnie FS, Breuer J, Parker S, Wallace V, Blackbeard J, Lever I, Kinchington PR Dickenson AH, Pheby T, Rice AS. Further characterization of a rat model of varicella zoster virus-associated pain: relationship between mechanical hypersensitivity and anxiety-related behavior, and the influence of analgesic drugs. Neuroscience 2007;144:1495-508.

[34] Hasnie FS, Wallace VC, Hefner K, Holmes A, Rice AS. Mechanical and cold hypersensitivity in nerve-injured $\mathrm{C} 57 \mathrm{BL} / 6 \mathrm{~J}$ mice is not associated with fear avoidance- and depression-related behaviour. $\mathrm{Br} J$ Anaesth 2007;98: 816-22.

[35] Hsieh JC, Belfrage M, Stone-Elander S, Hansson P, Ingvar M. Central representation of chronic ongoing neuropathic pain studied by positron emission tomography. PAIN ${ }^{\circledR}$ 1995;63:225-36.

[36] Hu Y, Yang J, Wang Y, Li W. Amitriptyline rather than lornoxicam ameliorates neuropathic pain-induced deficits in abilities of spatial learning and memory. Eur J Anaesthesiol 2010;27:162-8.
[37] Jensen K, Andersen HO, Olesen J, Lindblom U. Pressure-pain threshold in human temporal region. Evaluation of a new pressure algometer. PAIN ${ }^{\circledR}$ 1986;25:313-23.

[38] Ji G, Neugebauer V. Hemispheric lateralization of pain processing by amygdala neurons. J Neurophysiol 2009;102:2253-64.

[39] Kim JH, Suh SI, Seol HY, Oh K, Seo WK, Yu SW, Park KW, Koh SB. Regional grey matter changes in patients with migraine: a voxel-based morphometry study. Cephalalgia 2008;28:598-604.

[40] King T, Vera-Portocarrero L, Gutierrez T, Vanderah TW, Dussor G, Lai J, Fields HL, Porreca F. Unmasking the tonic-aversive state in neuropathic pain. Nat Neurosci 2009;12:1364-6.

[41] Kodama D, Ono H, Tanabe M. Increased hippocampal glycine uptake and cognitive dysfunction after peripheral nerve injury. PAIN ${ }^{\circledR}$ 2011;152:809-17.

[42] Kolber BJ, Montana MC, Carrasquillo Y, Xu J, Heinemann SF, Muglia LJ, Gereau RWT. Activation of metabotropic glutamate receptor 5 in the amygdala modulates pain-like behavior. J Neurosci 2010;30:8203-13.

[43] Kontinen VK, Kauppila T, Paananen S, Pertovaara A, Kalso E. Behavioural measures of depression and anxiety in rats with spinal nerve ligation-induced neuropathy. PAIN ${ }^{\circledR}$ 1999;80:341-6.

[44] Kuchinad A, Schweinhardt P, Seminowicz DA, Wood PB, Chizh BA, Bushnell MC. Accelerated brain gray matter loss in fibromyalgia patients: premature aging of the brain? J Neurosci 2007;27:4004-7.

[45] Leite-Almeida H, Almeida-Torres L, Mesquita AR, Pertovaara A, Sousa N Cerqueira JJ, Almeida A. The impact of age on emotional and cognitive behaviours triggered by experimental neuropathy in rats. PAIN ${ }^{\circledR}$ 2009;144:57-65.

[46] Lima D. Ascending pathways: anatomy and physiology. In: Basbaum AI, Bushnell MC, editors. Science of pain. Oxford: Academic Press; 2009. p. 477-526.

[47] Lindner MD, Plone MA, Francis JM, Cain CK. Chronic morphine reduces painrelated disability in a rodent model of chronic, inflammatory pain. Exp Clin Psychopharmacol 1999;7:187-97.

[48] Long DA. Hand differences and reported intensity of nociceptive stimuli. Percept Mot Skills 1994;79:411-7.

[49] Luerding R, Weigand T, Bogdahn U, Schmidt-Wilcke T. Working memory performance is correlated with local brain morphology in the medial frontal and anterior cingulate cortex in fibromyalgia patients: structural correlates of pain-cognition interaction. Brain 2008;131:3222-31.

[50] Lugo M, Isturiz G, Lara C, Garcia N, Eblen-Zaijur A. Sensory lateralization in pain subjective perception for noxious heat stimulus. Somatosens Mot Res 2002;19:207-12.

[51] Margolis RB, Krause SJ, Tait RC. Lateralization of chronic pain. PAIN ${ }^{\circledR}$ 1985;23:289-93.

[52] Matsuzawa-Yanagida K, Narita M, Nakajima M, Kuzumaki N, Niikura K, Nozaki H, Takagi T, Tamai E, Hareyama N, Terada M, Yamazaki M, Suzuki T. Usefulness of antidepressants for improving the neuropathic pain-like state and paininduced anxiety through actions at different brain sites. Neuropsychopharmacology 2007;33:1952-65.

[53] May A. Chronic pain may change the structure of the brain. PAIN ${ }^{\circledR}$ 2008;137:7-15.

[54] Meh D, Denislic M. Quantitative assessment of thermal and pain sensitivity. J Neurol Sci 1994;127:164-9.

[55] Merskey H, Watson GD. The lateralisation of pain. PAIN ${ }^{\circledR}$ 1979;7:271-80.

[56] Metz AE, Yau HJ, Centeno MV, Apkarian AV, Martina M. Morphological and functional reorganization of rat medial prefrontal cortex in neuropathic pain. Proc Natl Acad Sci USA 2009;106:2423-8.

[57] Millecamps M, Etienne M, Jourdan D, Eschalier A, Ardid D. Decrease in nonselective, non-sustained attention induced by a chronic visceral inflammatory state as a new pain evaluation in rats. PAIN ${ }^{\circledR} 2004 ; 109: 214-24$.

[58] Miller EK. The prefrontal cortex and cognitive control. Nat Rev Neurosci 2000;1:59-65.

[59] Miller EK, Cohen JD. An integrative theory of prefrontal cortex function. Annu Rev Neurosci 2001;24:167-202.

[60] Moayedi M, Weissman-Fogel I, Crawley AP, Goldberg MB, Freeman BV, Tenenbaum HC, Davis KD. Contribution of chronic pain and neuroticism to abnormal forebrain gray matter in patients with temporomandibular disorder. Neuroimage 2011;55:277-86.

[61] Moriarty O, McGuire BE, Finn DP. The effect of pain on cognitive function: a review of clinical and preclinical research. Prog Neurobiol 2011;93:385-404.

[62] Narita M, Kaneko C, Miyoshi K, Nagumo Y, Kuzumaki N, Nakajima M, Nanjo K, Matsuzawa K, Yamazaki M, Suzuki T. Chronic pain induces anxiety with concomitant changes in opioidergic function in the amygdala. Neuropsychopharmacology 2006;31:739-50.

[63] Narita M, Kuzumaki N, Narita M, Kaneko C, Hareyama N, Miyatake M, Shindo K, Miyoshi K, Nakajima M, Nagumo Y, Sato F, Wachi H, Seyama Y, Suzuki T. Chronic pain-induced emotional dysfunction is associated with astrogliosis due to cortical delta-opioid receptor dysfunction. J Neurochem 2006;97:1369-78.

[64] Pais-Vieira M, Lima D, Galhardo V. Sustained attention deficits in rats with chronic inflammatory pain. Neurosci Lett 2009;463:98-102.

[65] Pais-Vieira M, Mendes-Pinto MM, Lima D, Galhardo V. Cognitive impairment of prefrontal-dependent decision-making in rats after the onset of chronic pain. Neuroscience 2009;161:671-9.

[66] Pauli P, Wiedemann G, Nickola M. Pain sensitivity, cerebral laterality, and negative affect. PAIN ${ }^{\circledR} 1999 ; 80: 359-64$. 
[67] Pauli P, Wiedemann G, Nickola M. Pressure pain thresholds asymmetry in leftand right-handers: associations with behavioural measures of cerebral laterality. Eur J Pain 1999;3:151-6.

[68] Ren WJ, Liu Y, Zhou LJ, Li W, Zhong Y, Pang RP, Xin WJ, Wei XH, Wang J, Zhu $\mathrm{HQ}$, Wu CY, Qin ZH, Liu G, Liu XG. Peripheral nerve injury leads to working memory deficits and dysfunction of the hippocampus by upregulation of TNFalpha in rodents. Neuropsychopharmacology 2011;36:979-92.

[69] Robbins TW. Chemistry of the mind: neurochemical modulation of prefrontal cortical function. J Comp Neurol 2005;493:140-6.

[70] Rodriguez-Raecke R, Niemeier A, Ihle K, Ruether W, May A. Brain gray matter decrease in chronic pain is the consequence and not the cause of pain. $J$ Neurosci 2009;29:13746-50.

[71] Roeska K, Ceci A, Treede RD, Doods H. Effect of high trait anxiety on mechanical hypersensitivity in male rats. Neurosci Lett 2009;464:160-4.

[72] Roeska K, Doods H, Arndt K, Treede RD, Ceci A. Anxiety-like behaviour in rats with mononeuropathy is reduced by the analgesic drugs morphine and gabapentin. PAIN ${ }^{\circledR}$ 2008;139:349-57.

[73] Rolke R, Baron R, Maier C, Tolle TR, Treede RD, Beyer A, Binder A, Birbaumer N, Birklein F, Botefur IC, Braune S, Flor H, Huge V, Klug R, Landwehrmeyer GB, Magerl W, Maihofner C, Rolko C, Schaub C, Scherens A, Sprenger T, Valet M, Wasserka B. Quantitative sensory testing in the German Research Network on Neuropathic Pain (DFNS): standardized protocol and reference values. PAIN ${ }^{\circledR}$ 2006;123:231-43.

[74] Rolke R, Magerl W, Campbell KA, Schalber C, Caspari S, Birklein F, Treede RD. Quantitative sensory testing: a comprehensive protocol for clinical trials. Eur J Pain 2006;10:77-88.

[75] Rossi S, Miniussi C, Pasqualetti P, Babiloni C, Rossini PM, Cappa SF. Age-related functional changes of prefrontal cortex in long-term memory: a repetitive transcranial magnetic stimulation study. J Neurosci 2004;24:7939-44.

[76] Salzman CD, Fusi S. Emotion, cognition, and mental state representation in amygdala and prefrontal cortex. Annu Rev Neurosci 2010;33:173-202.

[77] Sarlani E, Farooq N, Greenspan JD. Gender and laterality differences in thermosensation throughout the perceptible range. PAIN ${ }^{\circledR} 2003 ; 106: 9-18$.

[78] Schaffner N, Wittwer A, Kut E, Folkers G, Benninger DH, Candia V. Heat pain threshold and tolerance show no left-right perceptual differences at complementary sites of the human forearm. Neurosci Lett 2008;440:309-13.

[79] Schiff BB, Gagliese L. The consequences of experimentally induced and chronic unilateral pain: reflections of hemispheric lateralization of emotion. Cortex 1994;30:255-67.

[80] Schlereth T, Baumgartner U, Magerl W, Stoeter P, Treede RD. Left-hemisphere dominance in early nociceptive processing in the human parasylvian cortex. Neuroimage 2003;20:441-54.
81] Schmidt-Wilcke T, Luerding R, Weigand T, Jurgens T, Schuierer G, Leinisch E Bogdahn U. Striatal grey matter increase in patients suffering from fibromyalgia-a voxel-based morphometry study. PAIN ${ }^{\circledR}$ 2007;132:S109-16.

[82] Schwier C, Kliem A, Boettger MK, Bar KJ. Increased cold-pain thresholds in major depression. J Pain 2010;11:287-90.

[83] Seminowicz DA, Laferriere AL, Millecamps M, Yu JS, Coderre TJ, Bushnell MC. MRI structural brain changes associated with sensory and emotional function in a rat model of long-term neuropathic pain. Neuroimage 2009;47: 1007-14.

[84] Seminowicz DA, Wideman TH, Naso L, Hatami-Khoroushahi Z, Fallatah S, Ware MA, Jarzem P, Bushnell MC, Shir Y, Ouellet JA, Stone LS. Effective treatment of chronic low back pain in humans reverses abnormal brain anatomy and function. J Neurosci 2011;31:7540-50.

[85] Spernal J, Krieg JC, Lautenbacher S. Pain thresholds as a putative functional test for cerebral laterality in major depressive disorder and panic disorder. Neuropsychobiology 2003;48:146-51.

[86] Storkson RV, Kjorsvik A, Tjolsen A, Hole K. Lumbar catheterization of the spinal subarachnoid space in the rat. J Neurosci Methods 1996;65: 167-72.

[87] Sullivan RM, Gratton A. Prefrontal cortical regulation of hypothalamicpituitary-adrenal function in the rat and implications for psychopathology: side matters. Psychoneuroendocrinology 2002;27:99-114.

[88] Suzuki T, Amata M, Sakaue G, Nishimura S, Inoue T, Shibata M, Mashimo T. Experimental neuropathy in mice is associated with delayed behavioral changes related to anxiety and depression. Anesth Analg 2007;104: 1570-7.

[89] Urban R, Scherrer G, Goulding EH, Tecott LH, Basbaum AI. Behavioral indices of ongoing pain are largely unchanged in male mice with tissue or nerve injuryinduced mechanical hypersensitivity. PAIN ${ }^{\circledR} 2011 ; 152: 990-1000$.

[90] Wallace VC, Blackbeard J, Pheby T, Segerdahl AR, Davies M, Hasnie F, Hall S, McMahon SB, Rice AS. Pharmacological, behavioural and mechanistic analysis of HIV-1 gp120 induced painful neuropathy. PAIN ${ }^{\circledR} 2007 ; 133: 47-63$.

[91] Wallace VC, Blackbeard J, Segerdahl AR, Hasnie F, Pheby T, McMahon SB, Rice AS. Characterization of rodent models of HIV-gp120 and anti-retroviralassociated neuropathic pain. Brain 2007;130:2688-702.

[92] Weinstein S, Sersen EA. Tactual sensitivity as a function of handedness and laterality. J Comp Physiol Psychol 1961;54:665-9.

[93] Wolff BB, Krasnegor NA, Farr RS. Effect of suggestion upon experimental pain response parameters. Percept Mot Skills 1965;21:675-83.

[94] Yalcin I, Bohren Y, Waltisperger E, Sage-Ciocca D, Yin JC, Freund-Mercier M], Barrot M. A time-dependent history of mood disorders in a murine model of neuropathic pain. Biol Psychiatry 2011;70:946-53. 